\title{
FlowCAM: Sizing cells and understanding the impact of size distributions on biovolume of planktonic community structure
}

\author{
Hans Henrik Jakobsen*, Jacob Carstensen \\ Department of Bioscience, Aarhus University, Frederiksborgvej 399, PO Box 358, 4000 Roskilde, Denmark
}

\begin{abstract}
Instruments for in vivo identification and quantification of marine organisms are becoming more common, and the interpretation of data from these instruments is still evolving. In the present study, we compare the sizing performance of 3 instruments: (1) a black and white (B/W) FlowCAM II; (2) a BeckmanCoulter Multisizer III (MIII); and (3) an inverted microscope. We applied 3 different particle sizing algorithms available from the FlowCAM to suspensions of 5 different particle morphotypes (4 different phytoplankton species and a spherical NIST calibration bead). The FlowCAM generated size distributions similar to those reported by the MIII for the spherical calibration beads. However, differences in reported sizes emerged among FlowCAM algorithms as well as among instruments when applied to morphologically more complex particles, such as diatom chains. There was an immediate and substantial loss of cell counts when live cells were fixed in Lugol's solution, but only minor differences in cell size distributions among the different FlowCAM algorithms. The difference in sizing performance of the FlowCAM algorithms affects biovolume estimates of the natural plankton samples analysed. Species diversity was apparently higher in samples analysed by microscopy than with the FlowCAM, but the cell size distribution from the microscope was extremely narrow compared to FlowCAM and MIII. The present study demonstrates that the particle sizing algorithm has severe impact on the characteristics of the particle size distribution and on the total community biomass estimate.
\end{abstract}

KEY WORDS: FlowCAM $\cdot$ Particle size $\cdot$ Plankton spectra $\cdot$ Lugol's fixation $\cdot$ Sizing algorithms Resale or republication not permitted without written consent of the publisher

\section{INTRODUCTION}

Taxonomic identification and sizing of marine microorganisms are of great importance in the analysis of natural plankton food-webs. Particle size distribution, converted into biovolume or carbon, is one of the main food-web properties, and is used as state variable in many ecological models. Using this information, interactions among various trophic levels and export to the sea floor are quantified and studied. Automated optical instrumentation for in situ analysis and quantification of plankton size distributions has been developed over the last few decades. New instruments include towed platforms such as the video plankton recorder (VPR) and the optical plankton counter (OPC, now LOPC) (Davis et al. 1992, Herman et al. 2004). Protist plankton community structures are typically analysed under an inverted microscope (Utermöhl 1958). Automated optical devices that operate in the $<100 \mu \mathrm{m}$ particle size realm and are aimed at replacing inverted microscopy include instrumentations such as the automatic imaging FlowCAM (Sieracki et al. 1998), the Cytobot, and CytoBuoy flow cytometer. These instruments are available as submersible units (Sosik \& Olson 2007, Campbell et al. 2008, Thyssen et al. 2008) and as onboard instrumentation on autonomous underwater vehicles (Cunningham et al. 2003). Despite their potential, the use of optical plankton instruments is often hampered by various logistical, 
operational, or technical problems. Furthermore, the information they provide and their costs must be balanced against traditional microscopic plankton analysis. Hence, there is a need for comparisons that demonstrate the advantages and disadvantages of automated plankton particle analysis against standard methods such as manual microscopic analysis and particle sizing by electronic particle counters.

The FlowCAM was developed and described in detail by Sieracki et al (1998), who conducted a thorough analysis of counting and sizing of beads and live cells. The main strength of the FlowCAM is the availability of individual images of each particle counted. The images are tagged with optical properties such as size, fluorescence, and abundance. In this fashion, visual post inspections of the dominant species are possible, and grouping of particles based on multiple optical properties add to the analytical flexibility. The data allow rapid estimation of plankton species and biovolume within the analysed water sample, which in turn provides almost real-time information about the dynamics of the plankton community being studied. This rapid processing has been valuable for biovolume distribution analysis in field programs such as oceanographic cruises or mesocosm experiments, and in studying phytoplankton responses on seasonal time scales, including early warning and monitoring of potential harmful algae blooms (e.g. Sieracki et al. 1998, Buskey \& Hyatt 2006, Campbell et al. 2008, Nielsen et al. 2010, Pedersen et al. 2010).

The most commonly used fixative for microplankton is Lugol's iodine solution added to achieve final concentrations of 1 to $10 \%$ (hereafter termed Lugol's solution). However, Lugol's solution introduces fixation artefacts that affect cell concentration and size (Klein Breteler 1985, Choi \& Stoecker 1989, Jerome et al. 1993, Wiackowski et al. 1994a,b, MendenDeuer \& Lessard 2000, Broglio et al. 2004, Zarauz \& Irigoien 2008). Accessing loss in biovolume and cells due to Lugol's fixations is not trivial, because direct counts of individual protist in vivo are challenging. In contrast to most other microplankton community analysis methods, the FlowCAM is able to perform analysis of both single cells and whole plankton communities unaltered by fixation (e.g. Zarauz \& Irigoien 2008, Álvarez et al. 2011). Zarauz \& Irigoien (2008) studied the effect of Lugol's solution on protist communities using the FlowCAM and found that Lugol's solution preservation had adverse effects on both biovolume and cell numbers compared to fresh samples. Among the observed effects of Lugol's solution was the formation of large particle aggregates in the sizes fraction $>20 \mu \mathrm{m}$, while the size fraction from 8 to $20 \mu \mathrm{m}$ decreased (Zarauz \& Irigoien 2008). Similarly, species-specific loss between 0 to $40 \%$ of ciliates and phytoplankton cells has been observed after addition of Lugol's solution (Montagnes et al. 1994, Broglio et al. 2003, 2004).

Image-based sizing also involves some challenges. Most importantly, shape affects the results, and calibration beads are uniformly spherical while phytoplankton cells rarely are so. This makes comparison of the sizing performance between the 2 types of particles difficult in systems such as the FlowCAM. In the more recent versions of the FlowCAM software package, several particle size algorithms are available. Choosing the proper particle size algorithm is crucial, as less suitable algorithms have errors propagating into the biovolume estimates of the sampled particle community. Surprisingly, very little attention has so far been paid to choosing the proper sizing algorithm.

Other instruments that have been employed in the past to analyse particles in the $\mu \mathrm{m}$ range include Coulter counters. The technology behind Coulter counters is mature and well documented, and has been used in technical and scientific oceanographically applications since the mid 1950s (Coulter 1956).

The aim of the present study is to benchmark the performance of the various sizing algorithms offered by the FlowCAM against a Beckman Coulter Multisizer III (MIII). We also compare the effect of Lugol's fixation on single cells and whole plankton communities and compare Lugol's fixed plankton analysed by inverted microscopy and by FlowCAM. The aim here is to compare phytoplankton community structures, assessed by the widely used combination of inverted microscopy and settling chambers, with the FlowCAM. In this fashion we aim to bridge between modern methods and classical community analysis.

\section{MATERIALS AND METHODS}

\section{FlowCAM overview}

We used a B/W FlowCAM ${ }^{\mathrm{TM}}$ II (Fluid Imaging Technologies) controlled by the software package VisualSpreadSheet (VISP) version 1.5.16. Except for a few technological improvements, this instrument is identical to the original instrument outlined (Sieracki et al. 1998). The FlowCAM collects data either automatically at a fixed rate or in response to an external fluorescence or particle scatter trigger. All measurements in the present study were done using the automatic imaging mode. However, the basic particle siz- 
ing algorithms of images are the same regardless of the data acquisition method used. In the automatic imaging mode, a black and white line-scan camera collects and stores images 'cut' out of video frames that are processed at a fixed rate of 9 frames $\mathrm{s}^{-1}$. More recent versions of the FlowCAM than the one used here offer higher and customable image capture rates. The camera is illuminated by an infrared LED. A lens collimates the infrared led light to enhance image contrast. Because the size of individual frame pixels is known from a calibration procedure and the focal depth of the image is known, a volume of the captured frame can be calculated. Particles and their sizes are extracted from the individual image frames and separated into individual particle images and stored, while the instrument keeps track of the processed volume. Thus, the total cell abundance is the same irrespective of the algorithm used. However, the sample biomass and spectral distribution of a single species or a complex plankton community is strongly dependent on the sizing algorithm used. The automatic mode seems most useful for whole plankton community assessments and, depending on the lens used, is limited by the rather low sample volume processed. In the present study, the flow cell processes in a slightly modified fashion that allows continuous vertical feeding of the flow cell. Thus, samples are fed through the vertically mounted flow cell from a beaker mounted above, in a fashion that prevents particle sedimentation in the flow system. The samples were stirred by a small lab stirrer set at the lowest speed. In this study only a $10 \times$ objective was used in the FlowCAM, but other magnifications are optional. The dimension of the flow cell is determined by the objective. We used the $2 \times 0.1 \mathrm{~mm}(10 \times)$ flowcell, supplied from Vitrocom (Sieracki et al. 1998).

\section{Coulter counter reference}

A Beckman Coulter Multisizer III (MIII) particle counter was used as a reference for the FlowCAM. The MIII counts particles suspended in an electrolyte (seawater) using the particle electrical impedance (Coulter 1956). Particles are pumped through a narrow orifice separating 2 electrodes, between which a weak current flows. The voltage across the orifice is sensitive to changes in the impedance, which is proportional to the volume of the particles that pass through the orifice. The MIII was fitted with a $100 \mu \mathrm{m}$ orifice tube and regularly recalibrated using Beckman Coulter NIST standard beads, but no drift was found. The maximum particle concentration measureable by MIII is limited to concentrations given by the probability of 2 or more particle passing the orifice simultaneously (coincidence). For this reason, only particle concentrations $<45 \times 10^{3}$ particles $\mathrm{ml}^{-1}$ are considered here.

\section{Inverted microscope}

An Olympus IX71 inverted microscope was used to examine Lugol's fixed samples. Samples were let settle for $24 \mathrm{~h}$ in a $25 \mathrm{ml}$ Utermöhl chamber before microscopic analysis was conducted. At least 20 particles of each encountered species, and if possible 50 particles of the dominant species, were sized using a calibrated stage micrometer. Particle volumes were estimated by applying appropriate geometric shapes.

\section{Calibrations}

Size calibrations of the MIII and the FlowCAM were conducted prior to initial analysis using inert particles, $15 \mu \mathrm{m}$ Beckman Coulter NIST calibration beads, supplied by Beckman Coulter. The inverted microscope was calibrated using a calibrated stage micrometer. Additional parallel calibration counts were done in the microscope in gridded SedwickRafter chambers. However, since counting performance of the FlowCAM was similar to results reported in the literature (Sieracki et al. 1998), these data were omitted.

\section{Comparing FlowCAM size algorithms}

Particles used to compare size algorithms were spherical $15 \mu \mathrm{m}$ NIST calibration beads, the discshaped dinoflagellate Prorocentrum minimum, the box-shaped diatom Thalassiosira weissflogii, the longitudinal-rotational-symmetrical Rhodomonas salina, and the chain-forming diatom Skeletonema marinoi. Particle sizes were estimated in the FlowCAM by the 3 different sizing algorithms available. Briefly, these are: (1) the feret (FER) equivalent spherical diameter (ESD), (2) the area-based diameter (ABD) ESD, and (3) the ellipsoid (ELP) ESD calculated as if the particle were an ellipsoid rotated along the length axis. The FER dimensions are the measured distance between parallel lines tangent to the particles profile perpendicular to the objective. The FER ESD is calculated based on the average of 36 
measurements and output by the FlowCAM as the feret ESD (Fluid Imagine Technologies 2007). The $\mathrm{ABD}$ is the area-based diameter, measured as if all recorded pixels of an analysed particle were merged into the cross-sectional area of a sphere. The ELP ESD is calculated as the equivalent spherical diameter of a rotational ELP calculated from the length $(L)$ and width $(W)$ obtained directly from instrument output spreadsheet;

$$
\mathrm{ELP} \operatorname{ESD}=\left(L W^{2}\right)^{1 / 3}
$$

A dense solution containing the particles in question (>20000 particle $\mathrm{ml}^{-1}$ ) was divided into 2 aliquots. One aliquot was analysed immediately in the MIII (1 $\mathrm{ml}$ analysed) and in the FlowCAM (0.12 ml analysed). The second aliquot was fixed in acid Lugol's solution prepared according to Throndsen (1978) (4\% final concentration) in brown glass bottles and stored in the dark at $5^{\circ} \mathrm{C}$ immediately after fixation. The Lugol's fixed sample was likewise analysed in the FlowCAM less than $24 \mathrm{~h}$ after fixation. This allowed the effect of Lugol's solution fixation to be examined by comparing live and fixed cells analysed by the FlowCAM to parallel MIII analysis. All analyses were conducted in triplicate. Cell size distributions were approximately normal for the $15 \mu \mathrm{m}$ NIST calibration beads and Prorocentrum minimum, whereas Rhodomonas salina, Thalassiosira weissflogii, and Skeletonema marinoi were right-skewed in their cell size distributions and therefore approximated with the log-normal distribution. Differences between MIII and the FlowCAM algorithms (both fresh and Lugol's-fixed samples) were analysed for the calibration beads and the 4 species within the mixed-model framework using standard likelihood ratio test statistic (PROC MIXED in SAS version 9.2), which is approximately $\chi^{2}$-distributed with degrees of freedom equal to the increase in number of parameters for the alternative hypothesis. The model included means and variances specific to each analysis method and a random factor for the variation between triplicates. Furthermore, differences in cell abundance between fresh and Lugol's-fixed samples were analysed for different size intervals and FlowCAM algorithms using a 2 sample $t$-test (PROC TTEST in SAS version 9.2).

\section{Sizing effects on natural phytoplankton community analysis: FlowCAM versus manual microscopy}

A mixed plankton assemblage was prepared from natural seawater (NSW) collected at 'Skovshoved
Havn' at the coast north of Copenhagen, Denmark $\left(55^{\circ} 45^{\prime} \mathrm{N}, 12^{\circ} 36^{\prime} \mathrm{E}\right)$. NSW was sieved through $80 \mu \mathrm{m}$ gauze to remove metazoan predators. The sieved NSW was incubated on a slowly rotating plankton wheel for $2 \mathrm{~d}$ prior to analysis to increase cell abundance. A subsample was fixed with Lugol's solution ( $4 \%$ final concentration) and analysed with the FlowCAM. Another subsample was settled for $24 \mathrm{~h}$ in a $25 \mathrm{ml}$ Utermöhl chamber and analysed by an experienced taxonomist using an inverted microscope.

The analyses were conducted in triplicates and means and standard deviations were calculated. The taxonomist identified the genera of particles and, for the most dominant morphotypes, identified the species. At least 20 particles of each encountered species, and if possible 50 particles of the dominant species, were sized using a calibrated stage micrometer.

\section{Effect of Lugol's fixations on natural plankton size distribution}

NSW were collected off the field station Søminestationen situated in the Isefjord, Denmark $\left(55^{\circ} 44^{\prime} \mathrm{N}\right.$, $\left.11^{\circ} 48^{\prime} \mathrm{E}\right)$ at a $4 \mathrm{~m}$ depth. At the sampling time the site was characterised by a well-mixed water column with a salinity of 21 . The samples were brought to the laboratory in a cool box to maintain approximate in situ temperatures. In the laboratory the samples were divided into 2 aliquots. One sample aliquot was fixed with Lugol's solution in brown glass bottles and stored in the dark at $5^{\circ} \mathrm{C}$ for less than $24 \mathrm{~h}$ before the FlowCAM analysis. The other sample aliquot was analysed by the FlowCAM immediately after return to the laboratory. Each plankton sample was counted in triplicate for $20 \mathrm{~min}$. Sample biovolumes were calculated as outlined above in the section 'Comparing FlowCAM size algorithms' using the 3 algorithms and summarised into logarithmic bin sizes.

\section{RESULTS}

\section{Particle sizing}

The particle size distributions were binned into histograms and visualized in bin sizes ranging from $0.25 \mu \mathrm{m}$ (Rhodomonas salina) to $1 \mu \mathrm{m}$ (Skeletonema marinoi). The unit ppm (parts per million, equal to $1 \mathrm{~mm}^{3} \times \mathrm{l}^{-1}$ ) were used as a proxy for biovolume in all binned histograms. Means and standard errors (SEs) of the cell size distribution were calculated for the 
three FlowCAM algorithms (both fresh and Lugol'sfixed samples) and MIII (Table 1). The variation between triplicate samples was small and not significant for any of the analyses ( $p>0.15$ for all components in Table 1).

\section{$15 \mu \mathrm{m}$ NIST calibration beads}

The sizing of NIST beads yielded means around the expected $15 \mu \mathrm{m}$ for the MIII and the different FlowCAM algorithms used (Fig. 1a,b). There were significant differences among mean sizes of the FlowCAM algorithms $\left(\chi_{2}^{2}=5641.5 ; \mathrm{p}<0.0001\right)$ and between MIII and the algorithms (Table 1). However, the large number of observations allowed for detecting small differences in mean values despite the fact that they ranged less than $1 \mu \mathrm{m}$. SEs of the size distributions were almost $50 \%$ larger when the FlowCAM algorithms were used, and there was no significant difference between these SEs $\left(\chi_{2}^{2}=2.6 ; p=0.2725\right)$, but the SE of the size distribution was significantly higher for FlowCAM algorithms compared to MIII $\left(\chi_{1}^{2}=9402.3 ; \mathrm{p}<0.0001\right)$.

Table 1. Mean and standard error (SE) for cell sizes of analysed particles as well as the SE between triplicates. Differences between means of MIII and FlowCAM algorithms were tested as contrasts (p-values in last column) within the mixed modelling framework. See 'Materials and methods' for more detail about statistical test used. FlowCAM algorithms usedFER: feret; ABD: area-based diameter; ELP: ellipsoid

\begin{tabular}{|c|c|c|c|c|}
\hline & $\begin{array}{c}\text { Distribution mean } \\
(\mu \mathrm{m})\end{array}$ & $\begin{array}{c}\text { Distribution SE } \\
(\mu \mathrm{m})\end{array}$ & $\begin{array}{l}\text { SE between } \\
\text { triplicates }(\mu \mathrm{m})\end{array}$ & $\mathrm{p}$ \\
\hline \multicolumn{5}{|l|}{$15 \mu \mathrm{m}$ NIST calibration beads } \\
\hline Coulter MIII & 14.88 & 0.624 & 0.006 & \\
\hline FlowCAM (FER) & 15.45 & 0.888 & 0.187 & $<0.0001$ \\
\hline FlowCAM (ABD) & 14.66 & 0.892 & 0.187 & 0.0390 \\
\hline FlowCAM (ELP) & 15.12 & 0.900 & 0.187 & 0.0274 \\
\hline \multicolumn{5}{|l|}{ Prorocentrum minimum } \\
\hline Coulter MIII & 12.42 & 1.767 & 0.000 & \\
\hline FlowCAM (FER) & 12.97 & 1.658 & 0.061 & $<0.0001$ \\
\hline FlowCAM (ABD) & 10.85 & 1.603 & 0.061 & $<0.0001$ \\
\hline FlowCAM (ELP) & 12.23 & 1.674 & 0.061 & $<0.0001$ \\
\hline Lugol's-fixed FlowCAM (FER) & 13.42 & 2.554 & 0.124 & $<0.0001$ \\
\hline Lugol's -fixed FlowCAM (ABD) & 12.35 & 2.480 & 0.124 & 0.4642 \\
\hline Lugol's-fixed FlowCAM (ELP) & 12.54 & 2.571 & 0.124 & 0.1872 \\
\hline \multicolumn{5}{|l|}{ Rhodomonas salina $^{\mathrm{a}}$} \\
\hline Coulter MIII & 6.93 & 0.772 & 0.005 & \\
\hline FlowCAM (FER) & 8.32 & 1.106 & 0.005 & $<0.0001$ \\
\hline FlowCAM (ABD) & 7.32 & 1.158 & 0.005 & $<0.0001$ \\
\hline FlowCAM (ELP) & 7.53 & 1.131 & 0.005 & $<0.0001$ \\
\hline Lugol's-fixed FlowCAM (FER) & 8.59 & 1.936 & 0.017 & $<0.0001$ \\
\hline Lugol's-fixed FlowCAM (ABD) & 7.68 & 1.568 & 0.017 & $<0.0001$ \\
\hline Lugol's-fixed FlowCAM (ELP) & 7.66 & 1.499 & 0.017 & $<0.0001$ \\
\hline \multicolumn{5}{|l|}{ Thalassiosira weissflogii $^{\mathrm{a}}$} \\
\hline Coulter MIII & 12.38 & 1.433 & 0.000 & $<0.0001$ \\
\hline FlowCAM (FER) & 11.79 & 1.913 & 0.003 & $<0.0001$ \\
\hline FlowCAM (ABD) & 9.94 & 1.498 & 0.003 & $<0.0001$ \\
\hline FlowCAM (ELP) & 10.73 & 1.567 & 0.003 & $<0.0001$ \\
\hline Lugol's-fixed FlowCAM (FER) & 12.25 & 2.507 & 0.000 & $<0.0001$ \\
\hline Lugol's-fixed FlowCAM (ABD) & 11.11 & 1.639 & 0.000 & $<0.0001$ \\
\hline Lugol's-fixed FlowCAM (ELP) & 11.08 & 1.750 & 0.000 & $<0.0001$ \\
\hline \multicolumn{5}{|l|}{ Skeletonema marino $^{\mathrm{a}}$} \\
\hline Coulter MIII & 6.40 & 1.986 & 0.002 & \\
\hline FlowCAM (FER) & 19.79 & 18.270 & 0.058 & $<0.0001$ \\
\hline FlowCAM (ABD) & 7.72 & 4.023 & 0.058 & 0.0007 \\
\hline FlowCAM (ELP) & 8.22 & 4.727 & 0.058 & $<0.0001$ \\
\hline Lugol's-fixed FlowCAM (FER) & 13.59 & 10.207 & 0.105 & $<0.0001$ \\
\hline Lugol's-fixed FlowCAM (ABD) & 7.99 & 3.974 & 0.105 & 0.0096 \\
\hline Lugol's-fixed FlowCAM (ELP) & 7.78 & 3.872 & 0.105 & 0.0316 \\
\hline
\end{tabular}




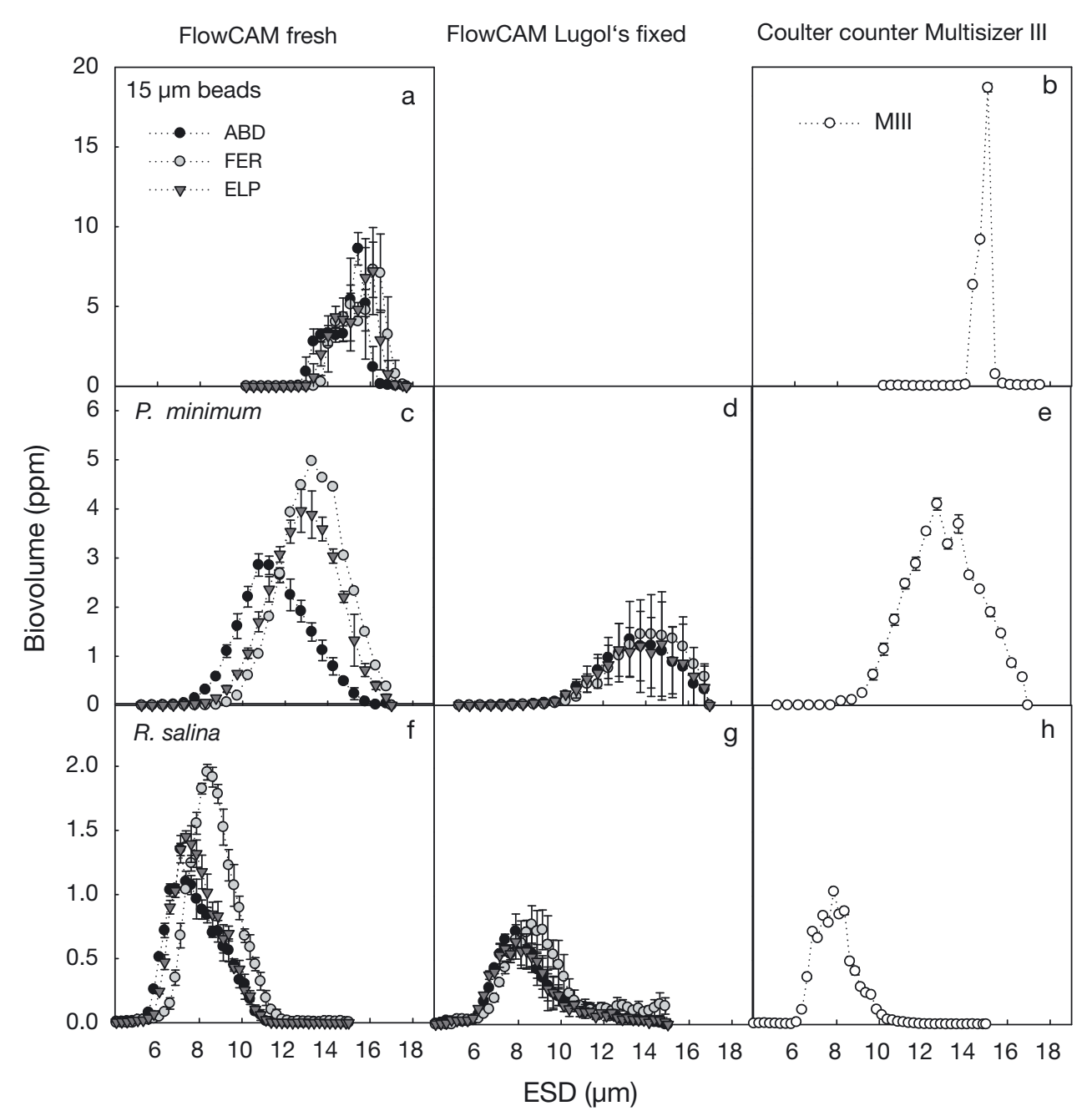

Fig. 1. Binned particle size volume distributions (part per million, ppm) versus bin size (equivalent spherical diameter, ESD [in $\mu \mathrm{m}])$. $(\mathrm{a}, \mathrm{b}) 15 \mu \mathrm{m}$ NIST calibration beads, $(\mathrm{c}, \mathrm{d}, \mathrm{e})$ disc-shaped Prorocentrum minimum and (f, $\mathrm{g}, \mathrm{h})$ the longitudinal, symmetrical cryptophyte Rhodomonas salina. Left column are FlowCAM measurements made on fresh unfixed cells; center column are FlowCAM measurements made on Lugol's fixed cells; and right column are measurements made with MIII. FlowCAM algorithms used-ABD: area-based diameter ESD; FER: ferer ESD; ELP: ellipsoid ESD

\section{Prorocentrum minimum}

The mean cell size ranged over $2.5 \mu \mathrm{m}$ for the different analyses applied to cultures of the disc-shaped dinoflagellate Prorocentrum minimum (Fig. 1c-e). Particularly, there were large and significant variation across the 3 FlowCAM algorithms $\left(\chi_{4}^{2}=6230.9 ; \mathrm{p}\right.$ $<0.0001$ ) with the ABD and FER algorithms yielding lowest and highest means, respectively (Table 1). The subsequent Lugol's fixation increased the cell size means for all the 3 FlowCAM algorithms $(t=$ 8.66; $\mathrm{p}<0.0001)$, and caused a large change in cell concentration (Fig. 2c). SEs of the distributions were similar across the 3 FlowCAM algorithms $\left(\chi_{4}^{2}=3.1\right.$; $\mathrm{p}=0.5412$ ), but SEs differed significantly between
MIII and FlowCAM analyses of fresh samples $\left(\chi_{1}^{2}=\right.$ 202.51; $\mathrm{p}<0.0001)$.

\section{Rhodomonas salina}

The mean cell size of the longitudinal symmetric cell Rhodomonas salina was significantly lower $(\sim 0.5$ to $1.5 \mu \mathrm{m}$ ) for samples analysed by means of MIII compared to FlowCAM (Table 1, Fig. 1f-h). There were also significant differences among the FlowCAM algorithms $\left(\chi_{4}^{2}=12910.7 ; \mathrm{p}<0.0001\right)$ with the FER algorithm yielding means almost $1 \mu \mathrm{m}$ larger than the other algorithms. Lugol's fixation of the samples also produced generally larger cell size estimates 


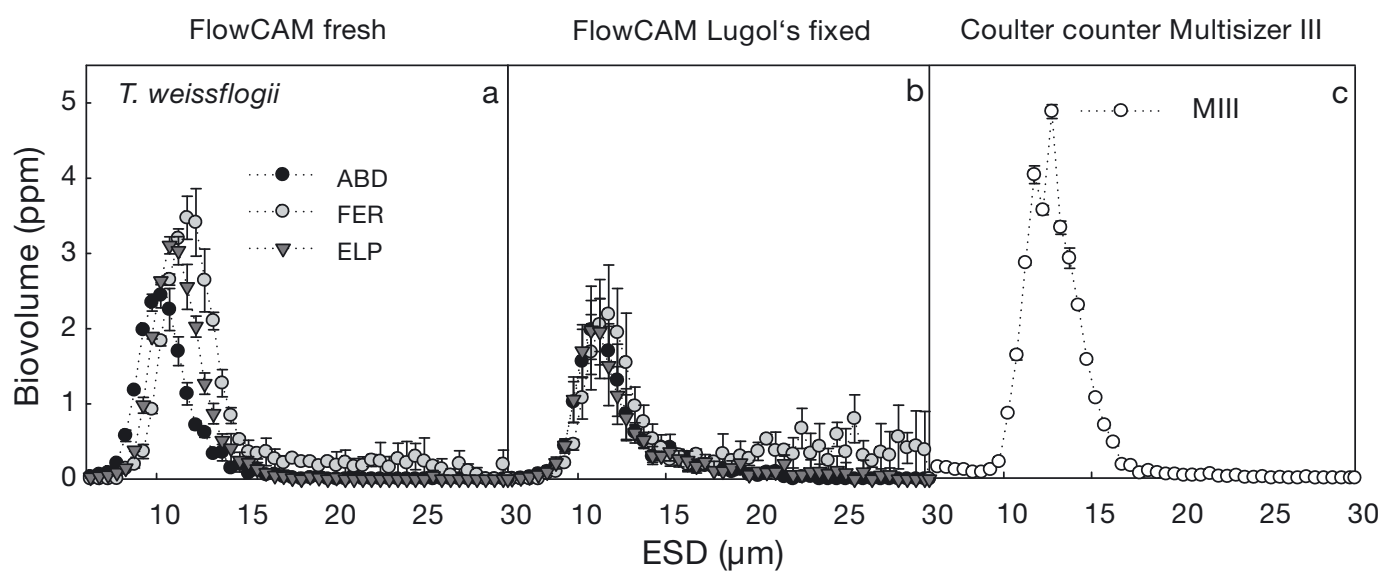

Fig. 2. Binned particle size distributions of the box-shaped diatom Thalassiosira weissflogii. Panels organised similar to Fig. 1

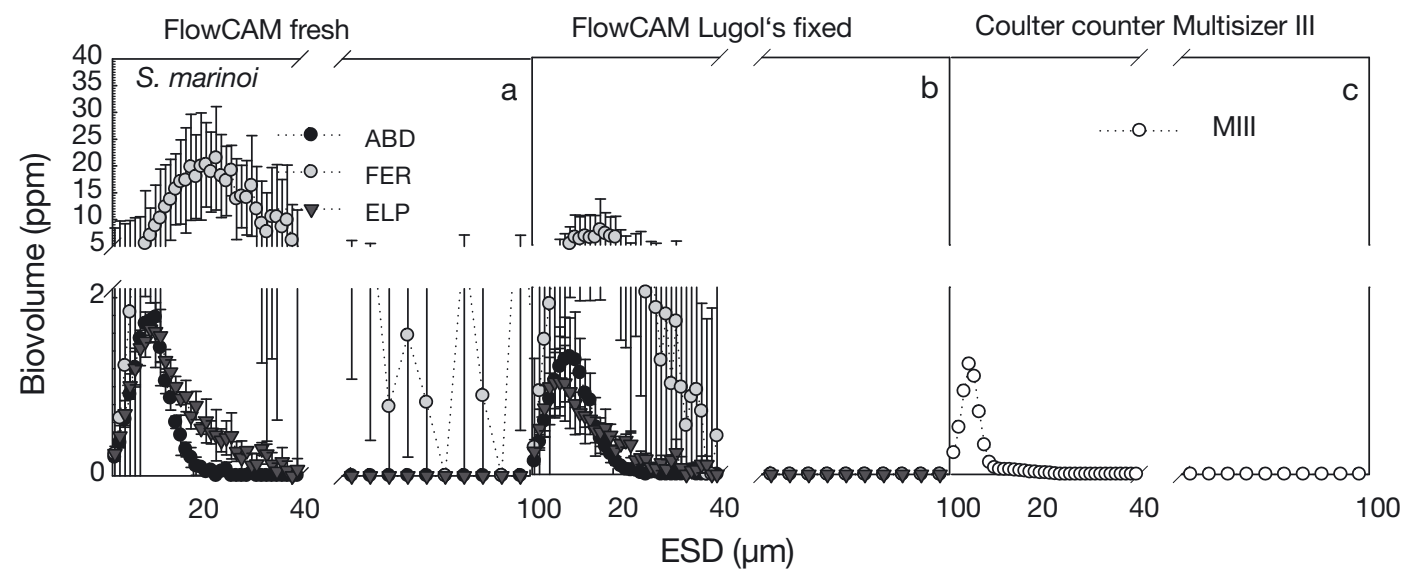

Fig. 3. Binned particle size distributions of the chain-forming diatom Skeletonema marinoi. Panels organised similar to Fig. 1

$(t=2.18 ; \mathrm{p}=0.0290)$ and less cell counts (Fig. 1g). SEs of the distributions even differed between FlowCAM algorithms $\left(\chi_{4}^{2}=934.9 ; \mathrm{p}<0.0001\right)$, most likely due to the wider distribution obtained with the FER algorithm applied to Lugol's-fixed samples (Table 1).

\section{Thalassiosira weissflogii}

The largest mean cell size for the box-shaped diatom Thalassiosira weissflogii was obtained with MIII, which was significantly higher than the means obtained with the FlowCAM (Table 1, Fig 1a-c). There were also significant differences between means from the three FlowCAM algorithms $\left(\chi_{4}^{2}=\right.$ 4400.2; $\mathrm{p}<0.0001$ ) with the FER algorithm yielding mean cell sizes $>1 \mu \mathrm{m}$ higher than the other algorithms. The cell size distributions estimated with the
FER algorithms also had significantly higher SEs than the other algorithms $\left(\chi_{4}^{2}=548.7 ; \mathrm{p}<0.0001\right)$. Lugol's fixation resulted in larger means $(t=20.93$; $\mathrm{p}<0.0001)$ and SEs of the cell size distribution.

\section{Skeletonema marinoi}

Cell size distributions of the chain-forming diatom Skeletonema marinoi obtained with the MIII and FlowCAM algorithms had significantly different means $\left(\chi_{4}^{2}=21539.0 ; \mathrm{p}<0.0001\right)$ and SEs $\left(\chi_{4}^{2}=\right.$ 8796.2; $\mathrm{p}<0.0001)$, with MIII having the lowest mean and lowest SE, while the FlowCAM FER algorithm had the largest mean and SE (Table 1, Fig. 3a,b). The FER algorithm estimated some large particle sizes that clearly exceeded the 2 other algorithms (Fig. 3). There was no general difference 
in the mean cell size for fresh and Lugol's-fixed samples $(t=1.31 ; \mathrm{p}=0.1899)$.

\section{Fresh vs. Lugol's-fixed cells at different size ranges}

Although there was a general loss of cells with Lugol's fixation and distribution means were higher, this pattern was not consistent for all size intervals (Table 2). Lugol's fixation typically reduced the number of Prorocentrum minimum cells in the mid-size range (between 6 and $10 \mu \mathrm{m}$ with the FER algorithm, and between 8 and $13 \mu \mathrm{m}$ with the 2 other algorithms). Cell abundances of Rhodomonas salina were significantly lower in the range from 5 to $10 \mu \mathrm{m}$, but there were significantly more cells in the Lugol's samples with sizes $<5 \mu \mathrm{m}$ and $>11 \mu \mathrm{m}$. Thalassiosira weissflogii had somewhat lower cell abundances for sizes $<13 \mu \mathrm{m}$, whereas there were higher abundances for sizes $>14 \mu \mathrm{m}$ in the Lugol's-fixed samples. Finally, there was no effect of Lugol's fixation on Skeletonema marinoi on cell abundance except for cell sizes $>20 \mu \mathrm{m}$ with the FER algorithm and $>12 \mu \mathrm{m}$ with the ELP algorithm. In general, Lugol's fixation resulted in more spread distributions of $P$. minimum, $R$. salina, and T. weissflogii, consistent with the increasing SE of the distributions (Table 1).

\section{Sizing of natural plankton assemblage}

The FlowCAM analysis of the Lugol's-fixed samples with mixed plankton (NSW) displayed the largest particle abundance in the range from 10 to $20 \mu \mathrm{m}$ (Fig. 4a). A visual inspection of the corresponding FlowCAM image collage revealed that
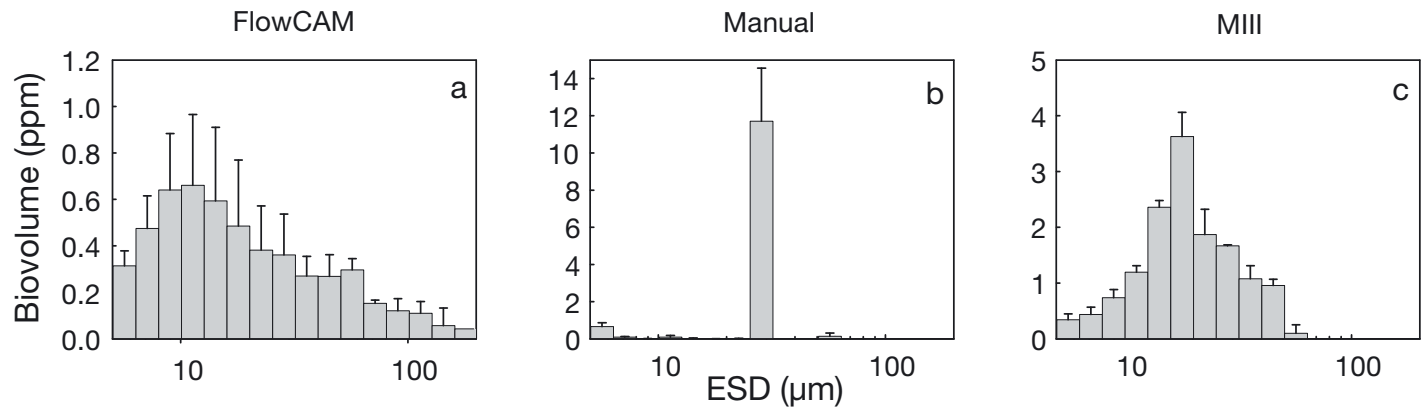

Fig. 4. Binned particle size distributions. (a) Lugol's-fixed natural seawater (NSW) analysed by the FlowCAM using the ELP algorithm (ellipsoid ESD). (b) Lugol's-fixed NSW analysed by the experienced taxonomist. (c) NSW analysed in the MIII. Error bars show \pm standard deviation (SD). Note the different scaling on the ordinate. The logarithmic size bins on the abscissa cor respond to $\log (1.5) \times$ cell volume. ESD is equal to equivalent spherical particle diameter $\left(\mathrm{ESD}_{i} \mu \mathrm{m}\right)$

Table 2. Probabilities for differences in cell abundances between fresh and Lugol's-fixed samples for different size intervals analysed by $t$-test ( $\mathrm{n}=3$ for each treatment). Variances for the 2 treatments were tested and pooled, if not significant ( $\mathrm{p} \geq 0.05)$. Significant differences $(p<0.05)$ between the 2 treatments are shown in bold, and increases in cell abundance for Lugol'sfixed samples are further emphasised with italics. See Table 1 for abbreviations. Cell size: cell size interval

\begin{tabular}{|c|c|c|c|c|c|c|c|c|c|c|c|c|}
\hline \multirow{2}{*}{$\begin{array}{l}\text { Cell size } \\
(\mu \mathrm{m})\end{array}$} & \multicolumn{3}{|c|}{ Prorocentrum minimum } & \multicolumn{3}{|c|}{ Rhodomonas salina } & \multicolumn{3}{|c|}{ Thalassiosira weissflogii } & \multicolumn{3}{|c|}{ Skeletonema marinoi } \\
\hline & FRE & ABD & ELP & FER & $\mathrm{ABD}$ & ELP & FER & ABD & ELP & FER & ABD & ELP \\
\hline$<5$ & 0.2666 & & & 0.0127 & 0.0322 & 0.3838 & 0.0028 & & & 0.8938 & 0.3523 & 0.4411 \\
\hline $5-6$ & 0.6375 & & 0.4490 & 0.1429 & 0.0002 & 0.2513 & 0.0025 & 0.0047 & & 0.1054 & 0.8051 & 0.6040 \\
\hline $6-7$ & 0.0021 & & 0.5007 & 0.0001 & 0.0000 & 0.0001 & 0.0764 & 0.0009 & 0.0185 & 0.1200 & 0.8182 & 0.5525 \\
\hline $7-8$ & 0.0006 & 0.3656 & 0.5062 & 0.0001 & 0.0017 & 0.0002 & 0.0200 & 0.0001 & 0.0659 & 0.2496 & 0.7260 & 0.9499 \\
\hline $8-9$ & 0.0003 & 0.0007 & 0.0047 & 0.0068 & 0.0712 & 0.0103 & 0.0378 & 0.0002 & 0.0901 & 0.2575 & 0.5114 & 0.7217 \\
\hline $9-10$ & 0.0037 & 0.0004 & 0.0008 & 0.0144 & 0.0528 & 0.0328 & 0.0043 & 0.0784 & 0.0071 & 0.5536 & 0.2865 & 0.2781 \\
\hline $10-11$ & 0.0595 & 0.0001 & 0.0007 & 0.6962 & 0.8360 & 0.4131 & 0.0414 & 0.2718 & 0.0653 & 0.6065 & 0.1833 & 0.1317 \\
\hline $11-12$ & 0.8641 & 0.0004 & 0.0013 & 0.0005 & 0.0121 & 0.0038 & 0.0122 & 0.2341 & 0.0270 & 0.9422 & 0.2387 & 0.0579 \\
\hline $12-13$ & 0.9753 & 0.0407 & 0.0064 & 0.0011 & 0.0374 & 0.0418 & 0.1033 & 0.0476 & 0.0234 & 0.6529 & 0.1944 & 0.0165 \\
\hline $13-14$ & & 0.9394 & 0.1094 & 0.0609 & 0.0260 & & & 0.0697 & 0.1643 & 0.4979 & 0.3121 & 0.0140 \\
\hline $14-15$ & & 0.4640 & 0.7771 & 0.0532 & & & & 0.0336 & 0.2536 & 0.9139 & 0.5116 & 0.0171 \\
\hline $15-20$ & & 0.2923 & & & & & & 0.1217 & 0.0249 & 0.2792 & 0.8267 & 0.0090 \\
\hline$>20$ & & & & & & & & & 0.0346 & 0.0026 & 0.8185 & 0.0112 \\
\hline
\end{tabular}


most of the particles in the 10 to $20 \mu \mathrm{m}$ range were chains of the diatoms Skeletonema costatum (0.47 ppm \pm SD $0.12 \mathrm{ppm}, \mathrm{n}=3$ ) and Dactyliosolen fragilissimus (0.29 ppm $\pm \mathrm{SD} 0.12 \mathrm{ppm}, \mathrm{n}=3$ ). Differences in the biovolume estimates between the ABD and ELP algorithms were $<20 \%$ (data not shown). The ABD ESD estimates of these 2 abundant species in the FlowCAM were $19.7 \mu \mathrm{m}$ at $180 \pm 67$ cells $\mathrm{ml}^{-1}$ and $12.4 \mu \mathrm{m}$ at $1081 \pm 150$ cells ml${ }^{-1}$ for $D$. fragilissimus and $S$. costatum, respectively. In comparison, the microscopically analysed natural plankton assemblage displayed a characteristic biovolume peak at around $35 \mu \mathrm{m}$ (Fig. 4b). However, this peak in the microscopically observed distribution was located at cell sizes above the most common cell sizes from the FlowCAM distribution. The abundance peak was similar to that obtained with the FlowCAM comprised of $D$. fragilissimus and $S$. costatum (12 and $0.6 \mathrm{ppm}$, respectively; Table 3) with cell

Table 3. Diversity table obtained by the microscopically analyzed mixed plankton assemblage. $L$ : length, $W$ : width

\begin{tabular}{|c|c|c|}
\hline & $\begin{array}{l}\text { Mean biovolume } \\
\quad\left(\mathrm{ppm}_{\mathrm{n}} \mathrm{n}=3\right)\end{array}$ & SD \\
\hline \multicolumn{3}{|l|}{ Athecate dinoflagellates } \\
\hline Naked dinoflagellates $10-20 \mu \mathrm{m}(L / W: 2)$ & $9.81 \times 10^{-3}$ & $4.25 \times 10^{-3}$ \\
\hline Naked dinoflagellates $10-20 \mu \mathrm{m}(L / W: 1.5)$ & $4.36 \times 10^{-3}$ & $7.55 \times 10^{-3}$ \\
\hline Amphidinium crassum/longum & $1.17 \times 10^{-2}$ & $5.49 \times 10^{-3}$ \\
\hline \multicolumn{3}{|l|}{ Thecate dinoflagellates } \\
\hline Thecate dinofl. $10-20 \mu \mathrm{m}$ & $6.98 \times 10^{-2}$ & $9.91 \times 10^{-2}$ \\
\hline Ceratium tripos & $1.16 \times 10^{-2}$ & $2.01 \times 10^{-2}$ \\
\hline \multicolumn{3}{|l|}{ Diatoms } \\
\hline Amphiprora sp. & $5.56 \times 10^{-3}$ & $1.82 \times 10^{-3}$ \\
\hline Centric spp. $20-30 \mu \mathrm{m}$ & $6.54 \times 10^{-3}$ & $5.67 \times 10^{-3}$ \\
\hline Centric spp. $30-40 \mu \mathrm{m}$ & $1.50 \times 10^{-3}$ & $2.59 \times 10^{-3}$ \\
\hline Centric spp. $60-70 \mu \mathrm{m}$ & $7.67 \times 10^{-2}$ & $1.09 \times 10^{-1}$ \\
\hline Centric spp. $70-80 \mu \mathrm{m}$ & $4.42 \times 10^{-2}$ & $4.42 \times 10^{-2}$ \\
\hline Chatoceros socialis/radians & $2.79 \times 10^{-1}$ & $1.48 \times 10^{-1}$ \\
\hline Dactyliosolen fragilissimus & 12.01 & 3.03 \\
\hline Nitzschia cf. closterium & $2.26 \times 10^{-3}$ & $2.86 \times 10^{-3}$ \\
\hline Pennate spp. $10-20 \mu \mathrm{m}$ & $1.24 \times 10^{-2}$ & $7.30 \times 10^{-3}$ \\
\hline Pennate spp. $20-30 \mu \mathrm{m}$ & $3.58 \times 10^{-4}$ & $3.19 \times 10^{-4}$ \\
\hline Pennate spp. $60-70 \mu \mathrm{m}$ & $1.08 \times 10^{-2}$ & $1.08 \times 10^{-2}$ \\
\hline Pennate spp. $70-80 \mu \mathrm{m}$ & $9.66 \times 10^{-3}$ & $1.04 \times 10^{-2}$ \\
\hline Skeletonema sp. & $6.09 \times 10^{-1}$ & $1.17 \times 10^{-1}$ \\
\hline Thallassionema nitzschioides & $1.55 \times 10^{-2}$ & $2.59 \times 10^{-3}$ \\
\hline \multicolumn{3}{|l|}{ Flagellates } \\
\hline Flagellates $<5 \mu \mathrm{m}$ & $2.24 \times 10^{-2}$ & $3.54 \times 10^{-3}$ \\
\hline Flagellates $5-10 \mu \mathrm{m}$ & $1.20 \times 10^{-1}$ & $3.76 \times 10^{-2}$ \\
\hline Flagellates $10-15 \mu \mathrm{m}$ & $5.68 \times 10^{-3}$ & $9.84 \times 10^{-3}$ \\
\hline \multicolumn{3}{|l|}{ Ciliates } \\
\hline Mesodinium rubrum & $8.37 \times 10^{-4}$ & $1.45 \times 10^{-3}$ \\
\hline Round ciliates $(10-20 \mu \mathrm{m})$ & $9.81 \times 10^{-3}$ & $1.70 \times 10^{-2}$ \\
\hline Elongate ciliates $(20-30 \mu \mathrm{m})$ & $1.74 \times 10^{-4}$ & $3.02 \times 10^{-4}$ \\
\hline Strombidinium-like $(20-30 \mu \mathrm{m})($ cone shaped) & $1.23 \times 10^{-3}$ & $1.08 \times 10^{-3}$ \\
\hline
\end{tabular}

Table 4. Integrated biovolume (ppm) of natural seawater (NSW)-analysed sample generated by the FlowCAM (ellipsoid [ELP] algorithm), the MIII and manually by the taxonomist. The FlowCAM biovolume is estimated using the ELP particle size algorithm

\begin{tabular}{|lcc|}
\hline & Biovolume (ppm) & SD \\
\hline FlowCAM (Lugol's fixed) & 5.29 & 1.7 \\
MIII (fresh unfixed) & 13.34 & 2.9 \\
Manual count (Lugol's fixed) & 14.75 & 1.4 \\
\hline
\end{tabular}

ESD of $26.6 \mu \mathrm{m}$ at $6995 \pm 635$ cells ml $^{-1}$ and $5.5 \mu \mathrm{m}$ at $1053 \pm 235$ cells ml ${ }^{-1}$ for $D$. fragilissimus and $S$. costatum, respectively. The MIII counts had a cell size distribution with a range slightly smaller than the FlowCAM and a peak similar to the manual counts (Fig. 4c). There was no camera attached to the MIII, and it was not possible to identify the dominant species in the distribution peak to cross-check these with the FlowCAM images or manual counts. The total biovolumes from the 3 methods varied with the FlowCAM analysis yielding the lowest values while the MIII and the manual analysis generated similar biovolumes (Table 4).

\section{Effect of Lugol's fixations on the size distribution}

The particle size distribution of the FlowCAM was estimated by the $\mathrm{ABD}, \mathrm{FER}$, or the ELP algorithms both for the freshly analysed and for the Lugol's-fixed samples on 2 separate days (Fig. 5). On 10 October, the smaller particle was dominated by asymmetrical dinoflagellates with morphologies similar to Heterocapsa rotundata and small diatoms, whereas the larger size classes were dominated by naked dinoflagellates and ciliates (Fig. 5a). Four weeks later, on 12 November, there was a small bloom of $H$. triquetra (identified from image collage; data not shown) with abundances peaking around 15 to $20 \mu \mathrm{m}$ (Fig. 5b), and for the larger cell sizes the particles were mostly Skeletonema spp. chains with a few oligotrich ciliates in the range from 30 to 
$60 \mu \mathrm{m}$ (Fig. 5b). When the biomasses were binned in logarithmic bins, there was a more or less constant biovolume distribution in each bin for the ABD and the ELP algorithm, except for some small peaks made by the cell mentioned above with this paragraph (Table 5, Fig. 5a,b). The FER algorithm yielded much higher total biovolume in all size classes and suggested the biovolume increased with increasing particle diameter at both the studied dates (Fig. 5a,b). In the November sample, we also observed an almost 4fold higher biomass in the smallest bin category. Lugol's fixation reduced abundances in all size bins regardless of the algorithm used (Fig. 5c,d). More important, fixation also changed the particle size

Table 5. Community biovolume (ppm) at Søminenstationen during the 2 sampling days. The biomasses are estimated using each of the 3 algorithms available with the FlowCAM. See Table 1 for abbreviation

\begin{tabular}{|c|c|c|c|c|c|c|}
\hline \multirow{2}{*}{$\begin{array}{l}\text { Date } \\
(2007)\end{array}$} & \multicolumn{2}{|c|}{$\begin{array}{c}\text { ABD } \\
\text { Fresh Lugol's }\end{array}$} & \multicolumn{2}{|c|}{$\begin{array}{c}\text { FER } \\
\text { Fresh Lugol's }\end{array}$} & \multicolumn{2}{|c|}{$\begin{array}{c}\text { ELP } \\
\text { Fresh Lugol's }\end{array}$} \\
\hline & 1.8 & 0.2 & 9.8 & 1.6 & 3.4 & 0.3 \\
\hline Nov 12 & 2.5 & 0.3 & 18.3 & 1.8 & 3.3 & 0.4 \\
\hline
\end{tabular}

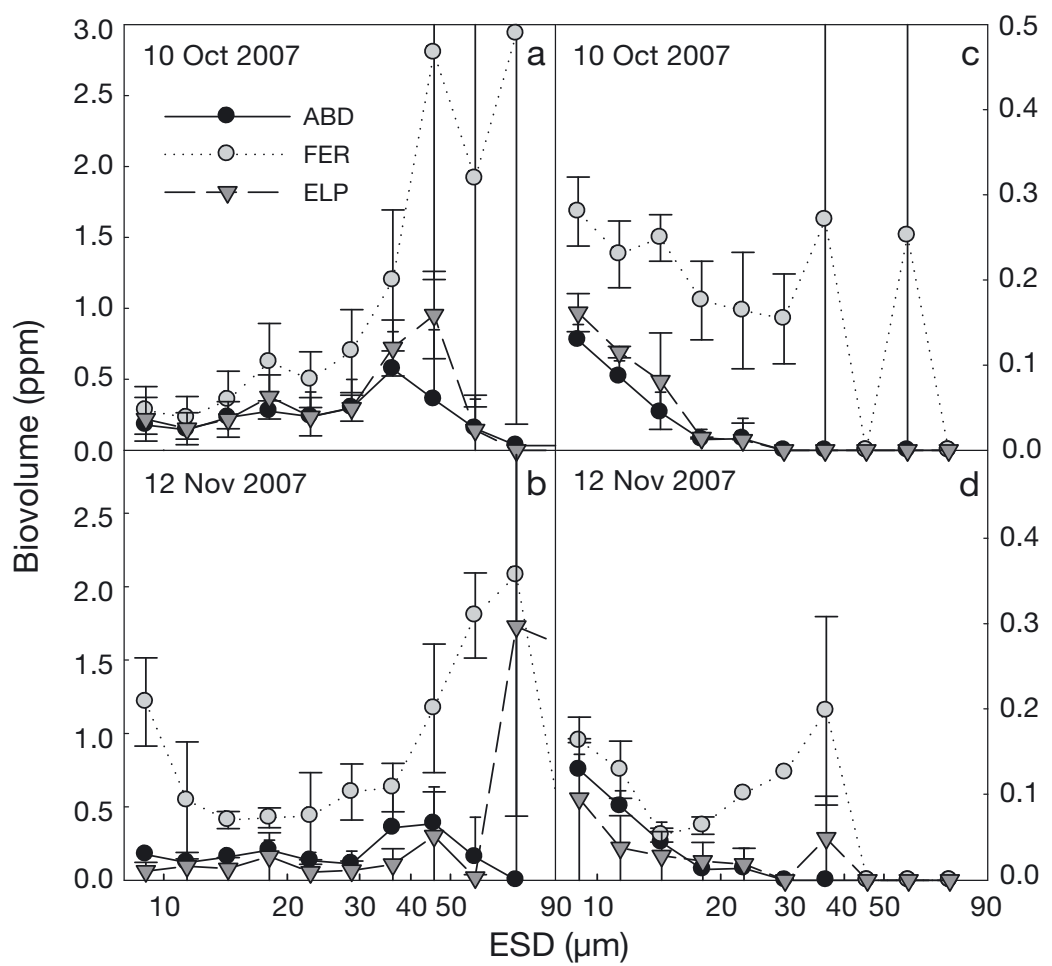

Fig. 5. Natural sea water analyzed by the FlowCAM. Binned biovolumes of particle size distribution against equivalent spherical diameter (ESD). (a,b) freshly analyzed and (c,d) corresponding samples fixed with Lugol's solution. The logarithmic size bins on the abscissa correspond to $\log (1.5) \times$ cell volume. See Table 1 for abbreviations distribution towards smaller cells in all 3 algorithms used, which in turn resulted in an underestimation of the plankton community biovolume (Table 5).

\section{DISCUSSION}

Optical plankton analysis can reveal important characteristics of the analysed sample, but the characteristics are biased by the method employed. Comparing the sizes estimated from images by the FlowCAM to those estimated by the MIII, there are a few generalities to observe. First, the FlowCAM particle analysis gave sizes that were identical to the MIII only for the $15 \mu \mathrm{m}$ NIST and using the ABD and ELP algorithms (Table 1, Fig. 1a). Among the remaining unfixed particle measurements, only Skeletonema marinoi ABD size was similar to that of MIII (Table 1, Fig. 3a,c). All other cell types had significant differences between FlowCAM and the MIII. Second, increasing particle morphological complexity such as the chains observed in the $S$. marinoi increased the difference between FlowCAM algorithms and the MIII. In the study by Sieracki et al. (1998) of single particles, FlowCAM estimated sizes were found to match microscopically measured particles. The most likely reasons for this are that we used MIII as a reference rather than a microscope and that the morphological complexity of $S$. marinoi specimens may have been higher than the diatoms used in the past.

The 3 available FlowCAM sizing algorithms worked well and yielded more or less similar cell sizes when particles were spherical, and only minor differences between the FER, $A B D$, or the ELP algorithms were found. Diatoms, on the other hand, seem to be the most challenging particles to size. Diatom chains are made of individual frustules that are more or less loosely connected. In the MIII the inter-connections between the frustules may break by the impedance current of the MIII. Thus, MIII records the particle volume of individual cell in the chain, while the FlowCAM imaging ignores the interspaces between individual cells of the chain. MIII found an average particle size of about $6.5 \mu \mathrm{m}$ for the chain-forming diatom Skele- 
tonema marinoi, while the FlowCAM suggested that the chain sizes ranged between 7.5 and $8.2 \mu \mathrm{m}$ for $\mathrm{ABD}$ and the ELP algorithms (Fig. 3a). The FlowCAM image collages reveal that the most dominant $S$. marinoi chain types were singles, doubles, and triples, with longer chains being less abundant. Thus, the sizing of the 2 instruments does not match very well for chain-forming species. The sizing discrepancy between the 2 instruments rests on instrumental differences, highlighting the difficulties associated with identifying the 'true' particle size of live cells. Finally, the FlowCAM FER algorithm produced a substantially larger size than the 2 alternative algorithms, with the ABD size estimate being closest to that obtained by the MIII, suggesting that the FER algorithm should be used with prudence.

Particle symmetry is, in fact, the most challenging single parameter in determining cell volumes from images. As an example, the average length:width ratio of Thalassiosira weissflogii is about 1.4. On the other hand, the FlowCAM images suggest that particles orientate in various directions relative to the camera during image capture, thus increasing the variance of the estimated mean size. A similar problem was presented by the disc-shaped cell Prorocentrum minimum, which could either be displayed as an elongate ellipsoid or as a sphere. This may explain why the SEs of the cell sizes were slightly higher in the FlowCAM estimates, except for Rhodomonas salina, which always oriented with the length axis perpendicular to the camera. However, the problem that 2-dimensional images present is not different from what microscopists have been handling for many of the past decades (Olenina et al. 2006).

A proper optical size estimate does not only depend on the sizing algorithm alone, but also on the instrument calibration and, most important, on the image resolution (Álvarez et al. 2011). Obviously, cells sampled at lower magnification are more difficult to size than cells sampled with higher magnification. In any case, flagellates smaller than Rhodomonas salina must be sized with the $20 \times$ objective, while larger particles are sizable with the $10 \times$ objective or even with the $4 \times$ objective, and results similar to the data presented here are in fact obtained with the $4 \times$ on large Gymnodinium sanguinium (data not shown). Thus, sizing and taxonomical resolution in the FlowCAM is also governed by the magnification used. It is therefore desirable to use the highest magnification possible for a given application to enhance particle sizing and to improve identification. The trade-off of increased magnification is a lower volume to be analysed, which may impact counting sta- tistics of the less abundant species. Alternatively, the FlowCAM analysis could be run for longer time to increase the sample volume processed.

In microscopic studies of Lugol's-fixed samples in the $>10 \mu \mathrm{m}$ particle size range, size estimates are based on an average of e.g. 50 measurements of each species. This approach introduces bias in the biovolume estimate if the sample e.g. contains diatom chains with variable chain lengths or if the diatoms frustules vary in size. This is also supported by the discrepancy in size distributions shown in Fig. 4. Moreover, there is a chance that a microscopically determined biomass and species composition is quite different from the 'true' biomass of the studied community due to the human factor effects. These may include human fatigue, boredom, and inexperience of the operator (Culverhouse et al. 2003, Culverhouse 2007). Comparing the integrated biovolumes of the Lugol's-fixed sample in the FlowCAM with the fresh NSW analysed in the MIII, there was a ca. $60 \%$ reduction in integrated sample biovolume (Fig. 5). Although this is a rather high loss ratio, it is close the range found in the comparison of unfixed single cells against Lugol's-fixed single cell, e.g. reported for ciliates (Broglio et al. 2003, 2004).

In the comparison of the total community biovolume between the manual microscopically analysis and the MIII, a close correspondence in total community biovolume was found (Table 4). However, the peak of the size distributions (modus) appeared positioned differently among the methods (Fig. 4). Moreover, the comparison between the 2 most dominant species in the microscopic analysis and in the FlowCAM suggested that abundance estimates differed between the 2 methods, which in turn cascaded into the disproportion between the characteristics of the particle size distribution and the total community biomass.

In the analysis of the different plankton communities from NSW sampled at Søminestationen, a large difference between the integrated plankton biovolumes of the different algorithms was found, with the FER being larger than 2 other algorithms. Fixing NSW with Lugol's solution changed the integrated biovolume and the particle size distributions dramatically. Most striking was the disappearance of large particles such as ciliates and single-celled large diatoms. Similar biovolume loss was also found for whole plankton communities (Klein Breteler 1985, Zarauz \& Irigoien 2008). The loss in cell counts and community structure may be a result of cell break up and release of cell organelles, which may aggregate into unrecognisable particle clusters. This is sup- 
ported by the appearance of a post-fixation peak of smaller particles (Klein Breteler 1985). The image resolution was too low in the present study to identify cell organelles outside the cells in the Lugol's-fixed treatments, but in the case of Lugol's-fixed Thalassiosira weissflogii (Fig. 2a), accumulation of larger fuzzy aggregates was observed in the FlowCAM viz. the observation by Klein Breteler (1985).

An important aspect of the present study is to compare the FlowCAM particle sizes and biovolumes with past measurement techniques. Such comparisons may influence our understanding of plankton ecology but also form a bridge between studies. Setting a FlowCAM protocol to address this type of question depends on the application. However, our work suggests that Lugol's solution should be avoided and that the ABD algorithm yields sizes that compare best with the Coulter counter Multisizer III. Additionally, the data of the present work imply that the Lugol's biovolume estimates of natural phytoplankton may be underestimated, an observation supported by Klein Breteler (1985) who also studied the fixation effect on whole plankton communities. Our observations of losses up to $50 \%$ in cell biomass agree well with the observation on fixation loss in ciliates by Broglio et al. (2004). Such underestimation ultimately cascades into food-web carbon flow rate estimates that in turn impact our current understanding of turnover processes the ocean.

Choosing the wrong sizing algorithm strongly influence the calculated bio-volumes. Additionally, to address the biomass of morphological complex plankton structures, such as chain-forming Skeletonema marinoi investigated here or large hollow Phaeocystis colonies that typify many shelf areas, the ABD algorithm seems to the most appropriate approach when using the FlowCAM.

Acknowledgements. This research is a contribution to the WISER project (contract \#FP7-226273), funded by the European Commission. We are indebted to the 3 anonymous reviewers who carefully reviewed and provided constructive critique that improved an earlier manuscript draft.

\section{LITERATURE CITED}

Álvarez E, Lopez-Urrutia Á, Nogueira E, Fraga S (2011) How to effectively sample the plankton size spectrum? A case study using FlowCAM. J Plankton Res 33: 1119-1133

> Broglio E, Jónasdottir SH, Calbet A, Jakobsen HH, Saiz E (2003) Effect of heterotrophic versus autotrophic food on feeding and reproduction of the calanoid copepod Acartia tonsa: relationship with prey fatty acid composition. Aquat Microb Ecol 31:267-278
Broglio E, Saiz E, Calbet A, Trepat I, Alcaraz M (2004) Trophic impact and prey selection by crustacean zooplankton on the microbial communities of an oligotrophic coastal area (NW Mediterranean Sea). Aquat Microb Ecol 35:65-78

Buskey EJ, Hyatt CJ (2006) Use of the FlowCAM for semiautomated recognition and enumeration of red tide cells (Karenia brevis) in natural plankton samples. Harmful Algae 5:685-692

Campbell L, Walpert JN, Guinasso NL (2008) A new buoybased in situ optical early warning system for harmful algal blooms in the Gulf of Mexico. Nova Hedwigia 133: 161-170

> Choi JW, Stoecker DK (1989) Effects of fixation on cell volume of marine planktonic protozoa. Appl Environ Microbiol 55:1761-1765

Coulter WH (1956). High speed automatic blood cell counter and cell analyser. Nat Electr Conf 12:1034-1040

Culverhouse PF (2007) Human and machine factors in algae monitoring performance. Ecol Inform 2:361-366

Culverhouse PF, Williams R, Reguera B, Herry V, GonzalezGil S (2003) Do experts make mistakes? A comparison of human and machine identification of dinoflagellates. Mar Ecol Prog Ser 247:17-25

> Cunningham A, Mckee D, Craig S, Tarran G, Widdicombe C (2003) Fine-scale variability in phytoplankton community structure and inherent optical properties measured from an autonomous underwater vehicle. J Mar Syst 43: $51-59$

Davis CS, Gallager SM, Berman MS, Haury LR, Strickler JR (1992) The Video Plankton Recorder (VPR): design and initial results. Arch Hydrobiol Beih Ergebn Limnol 36: $67-81$

Herman AW, Beanlands B, Phillips EF (2004) The next generation of optical plankton counter: the laser-OPC. J Plankton Res 26:1135-1145

Jerome CA, Montagnes DJS, Taylor FJR (1993) The effect of the quantitative protagol stain and Lugol's and Bouin's fixatives on cell size: a more accurate estimate of ciliate species biomass. J Eukaryot Microbiol 40:254-259

Klein Breteler WCM (1985) Fixation artefacts of phytoplankton in zooplankton grazing experiments. Hydrobiol Bull $1: 13-19$

Menden-Deuer S, Lessard EJ (2000) Carbon to volume relationships for dinoflagellates, diatoms, and other protist plankton. Limnol Oceanogr 45:569-579

> Montagnes DJS, Berges JA, Harrison PJ, Taylor FJR (1994) Estimating carbon, nitrogen, protein, and chlorophyll a from volume in marine phytoplankton. Limnol Oceanogr 39:1044-1060

> Nielsen LT, Jakobsen HH, Hansen PJ (2010) High resilience of two coastal plankton communities to twenty-first century seawater acidification: evidence from microcosm studies. Mar Biol Res 6:542-555

Olenina I, Hajdu S, Edler L, Andersson A and others (2006). Biovolumes and size-classes of phytoplankton in the Baltic Sea. HELCOM Baltic Sea Environment Proceedings 106

Pedersen TM, Almeda R, Fotel FL, Jakobsen HH, Mariani P, Hansen BW (2010) Larval growth in the dominant polychaete Polydora ciliata is food-limited in a eutrophic Danish estuary (Isefjord). Mar Ecol Prog Ser 407:99-110

Sieracki CK, Sieracki ME, Yentsch CS (1998) An imagingin-flow system for automated analysis of marine microplankton. Mar Ecol Prog Ser 168:285-296 
Sosik HM, Olson RJ (2007) Automated taxonomic classification of phytoplankton sampled with imaging-in-flow cytometry. Limnol Oceanogr Methods 5:204-216

Throndsen J (1978). Preservation and storage. In: Sournia A (ed) Monographs on oceanographic methodology. UNESCO, Paris, p 69-74

Thyssen M, Mathieu D, Garcia N, Denis M (2008) Shortterm variation of phytoplankton assemblages in Mediterranean coastal waters recorded with an automated submerged flow cytometer. J Plankton Res 30: $1027-1040$

Utermöhl H (1958) Zur Vervollkommung der quantitativen

Editorial responsibility: Josep Gasol,

Barcelona, Spain
Phytoplankton-Methodik. Mitt Int Ver Theor Angew Limnol 9:1-38

- Wiackowski K, Brett MT, Goldman CR (1994a) Differential effects of zooplankton species on ciliate community structure. Limnol Oceanogr 39:486-492

Wiackowski K, Doniec A, Fyda J (1994b) An empirical study of the effect of fixation on ciliate cell volume. Mar Microb Food Webs 8:59-69

Zarauz L, Irigoien X (2008) Effects of Lugol's fixation on the size structure of natural nano-microplankton samples, analyzed by means of an automatic counting method. J Plankton Res 30:1297-1303

Submitted: August 16, 2010; Accepted: September 11, 2011 Proofs received from author(s): November 10, 2011 